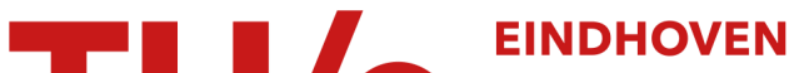 UNIVERSITY OF TECHNOLOGY
}

\section{Patterned Actuators via Direct Ink Writing of Liquid Crystals}

Citation for published version (APA):

del Pozo Puig, M., Sol, J. A. H. P., van Uden, S. H. P., Peeketi, A. R., Lugger, S. J. D., Annabattula, R. K., Schenning, A. P. H. J., \& Debije, M. G. (2021). Patterned Actuators via Direct Ink Writing of Liquid Crystals. ACS Applied Materials \& Interfaces, 13(49), 59381-59391. https://doi.org/10.1021/acsami.1c20348

\section{Document license:}

CC BY-NC-ND

DOI:

10.1021/acsami.1c20348

Document status and date:

Published: 15/12/2021

\section{Document Version:}

Publisher's PDF, also known as Version of Record (includes final page, issue and volume numbers)

\section{Please check the document version of this publication:}

- A submitted manuscript is the version of the article upon submission and before peer-review. There can be important differences between the submitted version and the official published version of record. People interested in the research are advised to contact the author for the final version of the publication, or visit the $\mathrm{DOI}$ to the publisher's website.

- The final author version and the galley proof are versions of the publication after peer review.

- The final published version features the final layout of the paper including the volume, issue and page numbers.

Link to publication

\section{General rights}

Copyright and moral rights for the publications made accessible in the public portal are retained by the authors and/or other copyright owners and it is a condition of accessing publications that users recognise and abide by the legal requirements associated with these rights.

- Users may download and print one copy of any publication from the public portal for the purpose of private study or research.

- You may not further distribute the material or use it for any profit-making activity or commercial gain

- You may freely distribute the URL identifying the publication in the public portal.

If the publication is distributed under the terms of Article 25fa of the Dutch Copyright Act, indicated by the "Taverne" license above, please follow below link for the End User Agreement:

www.tue.nl/taverne

Take down policy

If you believe that this document breaches copyright please contact us at:

openaccess@tue.nl

providing details and we will investigate your claim. 


\title{
Patterned Actuators via Direct Ink Writing of Liquid Crystals
}

\author{
Marc del Pozo, Jeroen A. H. P. Sol, Stefan H. P. van Uden, Akhil R. Peeketi, Sean J. D. Lugger, \\ Ratna K. Annabattula, Albert P. H. J. Schenning,* and Michael G. Debije*
}

Cite This: ACS Appl. Mater. Interfaces 2021, 13, 59381-59391

Read Online

ABSTRACT: Soft actuators allowing multifunctional, multishape deformations based on single polymer films or bilayers remain challenging to produce. In this contribution, direct ink writing is used for generating patterned actuators, which are in between single- and bilayer films, with multifunctionality and a plurality of possible shape changes in a single object. The key is to use the controlled deposition of a light-responsive liquid crystal ink with direct ink writing to partially cover a foil at strategic locations. We found patterned films with $40 \%$ coverage of the passive substrate by an

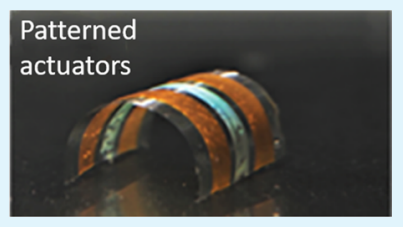
active material outperformed "standard" fully covered bilayers. By patterning the film as two stripes, a range of motions, including left- and right-handed twisting and bending in orthogonal directions, could be controllably induced in the same actuator. The partial coverage also left space for applying liquid crystal inks with other functionalities, exemplified by fabricating a light-responsive green reflective actuator whose reflection can be switched "on" and "off". The results presented here serve as a toolbox for the design and fabrication of patterned actuators with dramatically expanded shape deformation and functionality capabilities.

KEYWORDS: light-responsive actuators, direct ink writing, photonic actuators, liquid crystal elastomer, bilayer actuators, soft robotics

\section{INTRODUCTION}

Significant progress toward untethered, centimeter-scale soft actuators triggered by external stimuli has been made, ${ }^{1-4}$ and their appeal in robotics has been demonstrated. ${ }^{5-9}$ Among responsive materials, liquid crystal (LC) polymers are considered excellent options for fabricating this class of actuators, ${ }^{10-14}$ delivering large, rapid, and reversible preprogramed deformations triggered by a variety of stimuli, both in wet and dry environments. ${ }^{15,16}$ To date, there have been essentially three options for creating these LC-based actuators. In the first option, actuators are made from single film layers and generally only display single deformation modes depending on the molecular alignment fixed in the network, for example, contraction, ${ }^{17}$ bending, ${ }^{18}$ or twisting, ${ }^{19}$ typically triggered by a single stimulus. The second option is bilayer actuators of the active LC material on a passive foil or layer, which can improve the robustness of the device while delivering the same type of motions as single-layer films, ${ }^{20,21}$ although facilitating functional combinations in a single actuator such as light and magnetic responsivity or temperature response while having photonic properties. ${ }^{2-25}$ The third option consists of stacking multiple layers, resulting in a $3 \mathrm{D}$ object, ${ }^{6,11,26-28}$ which can be accomplished via different fabrication methods. ${ }^{3}$ This latter approach has the advantage that complex shape deformation can be accomplished that can result in self-propulsion, ${ }^{10,29}$ for example. However, achieving multiple deformation modes within the same actuator remains challenging. This calls for a new design concept that outperforms both single- and bilayer actuators to bring untethered soft actuators one step closer to widespread use. $^{30-32}$

Diverse motions from a single object are achieved in nature mostly through individual, sequential responses by discrete subunits that form the larger object: ${ }^{33}$ take, for example, the rotation of human hands, which is accomplished by the contraction/expansion of individual tendons. ${ }^{34}$ By translating this concept to untethered actuators, novel motions and control could be accomplished.

Patterned actuators are fabricated by selectively depositing an active material in specific regions atop a passive substrate. The presence of discrete active regions on a passive layer allows the use of less material than having to coat entire substrates, and for individual regions of the device to be independently activated and, as in tendons, trigger localized stresses and specific localized motions. Patterning has been employed in bilayer films to deliver folding, ${ }^{35}$ rolling, ${ }^{36}$ and curling, ${ }^{37}$ origami-like folding, ${ }^{38}$ out-of-plane shape deformations $^{39}$ or to induce 2D-to-3D shape changes in films. ${ }^{40}$ Additionally, temperature-responsive LC elastomers (LCE) acting as a sort of "skeletal muscles" within a passive material that triggers a shape change upon heating have also been reported. ${ }^{6,41}$ These examples show the potential of patterning, but its use to obtain multiple shape deformations within the same object remains unexplored. For this goal, employing light

Received: October 21, 2021

Accepted: November 19, 2021

Published: December 6, 2021

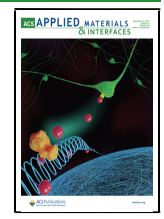



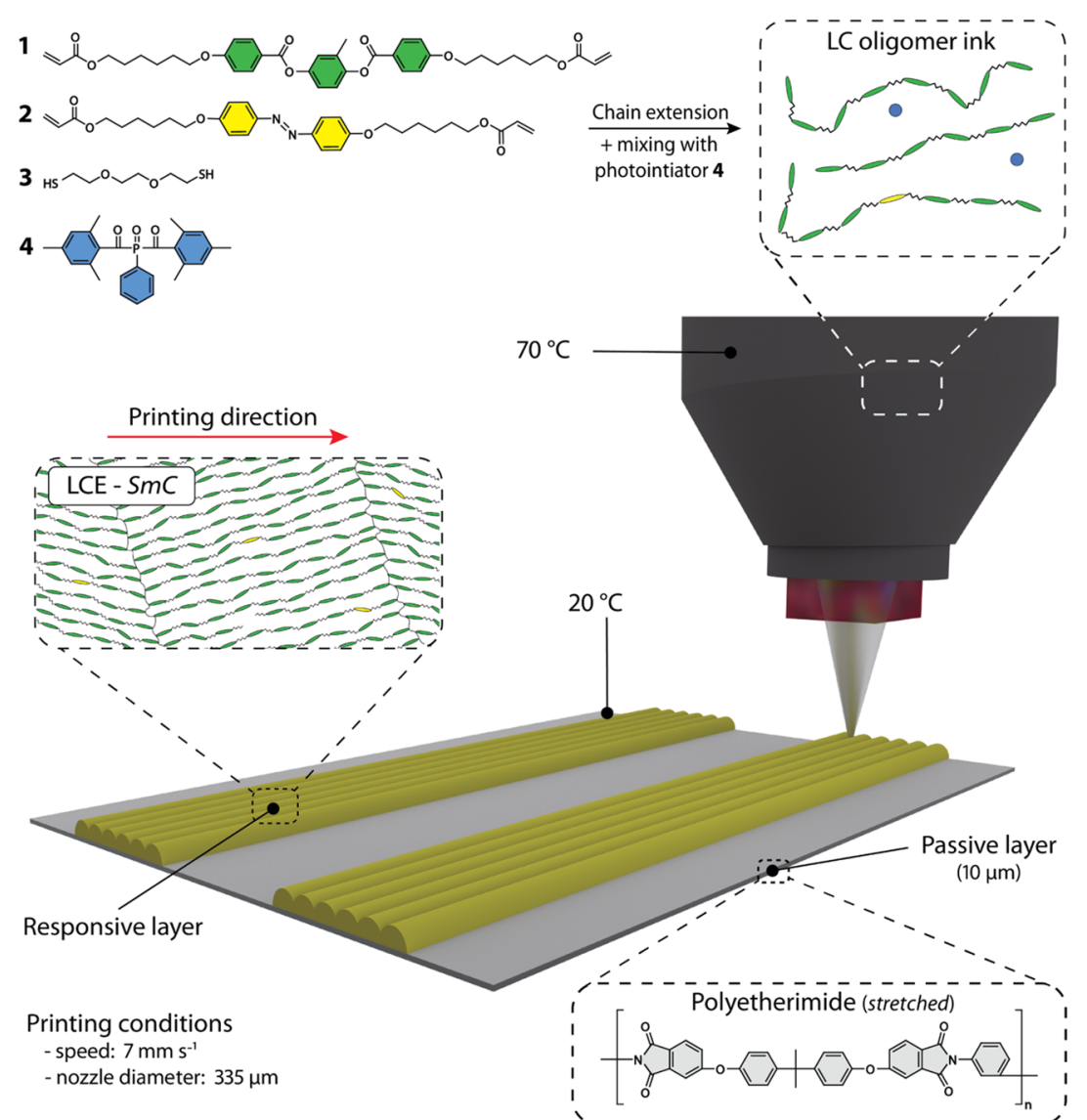

Figure 1. Scheme depicting the synthesis of the LC ink (top) and the fabrication process of an LC-based patterned actuator via DIW (bottom). The LC oligomer used to prepare the ink is the result of chain extension via a thiol-acrylate Michael addition of molecules 1-2 using $\mathbf{3}$ as a spacer. The insets show an idealized molecular alignment at each stage.
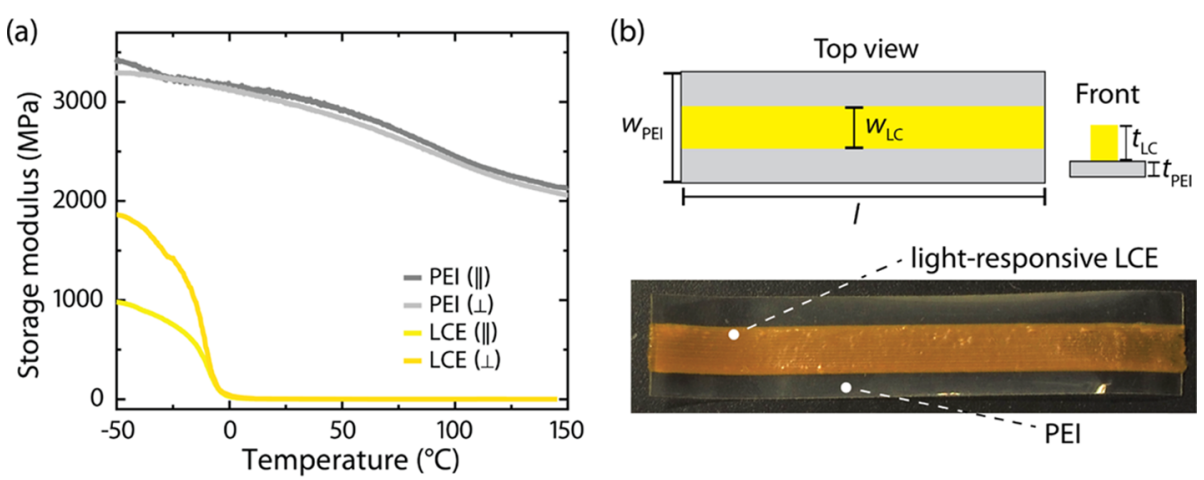

(c)
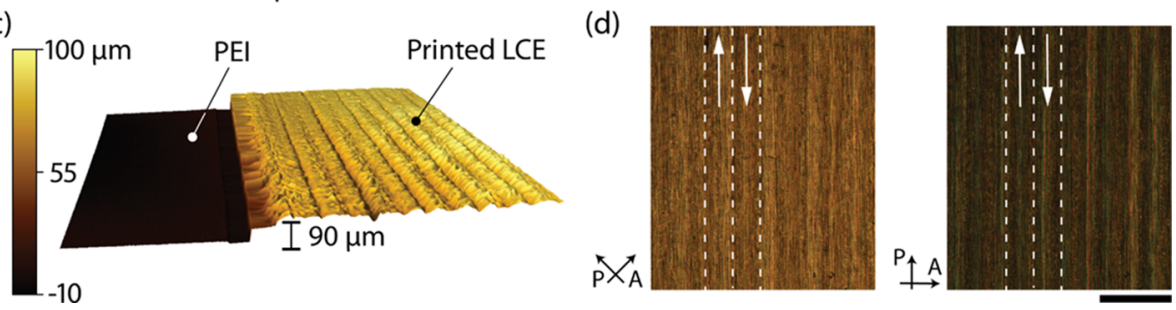

Figure 2. Characterization of the patterned film prepared via DIW. (a) Storage modulus as a function of the temperature of the two layers separately. The modulus was investigated parallel $(\|)$ and perpendicular $(\perp)$ to the alignment direction of the LC and to the stretching direction of the PEI foil. (b) Schematic representation of a patterned film in which the different tunable design parameters are defined (top). Yellow and light gray represents the LCE and the PEI, respectively (bottom). A photograph of a fabricated $5 \times 25 \mathrm{~mm}^{2}$ film with $40 \%$ coverage. (c) $3 \mathrm{D}$ profile of the edge of the printed LCE. (d) Crossed polarized light micrographs of the printed LCE on the foil. The black arrows represent the directions of the polarizer $(\mathrm{P})$ and analyzer $(\mathrm{A})$. The white dashed lines indicate the borders of the printed lines. The white arrows indicate the direction of printing. The scale bar represents $500 \mu \mathrm{m}$. 
(a)

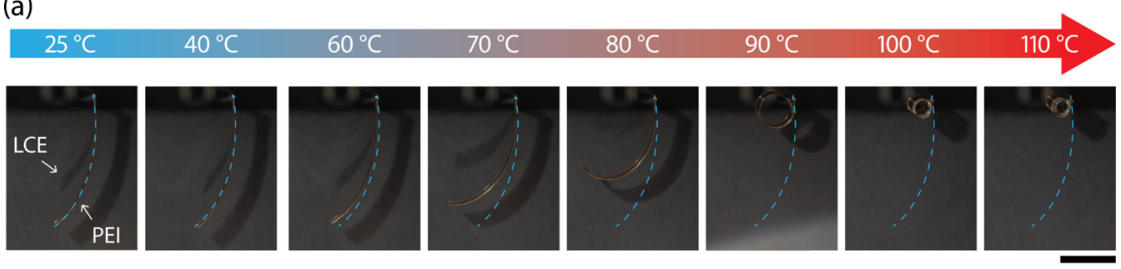

(b)

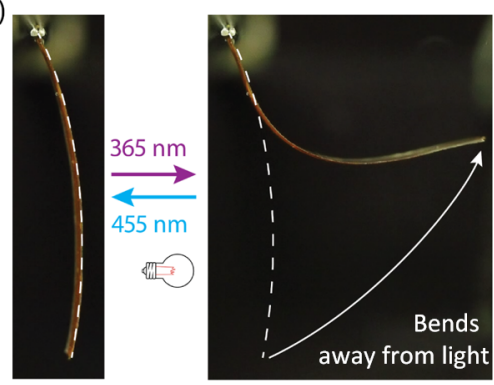

(c)

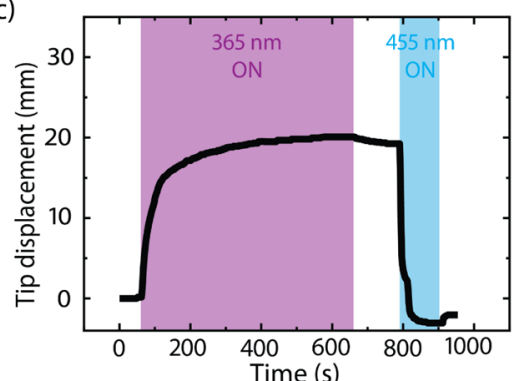

Figure 3. Stimuli response of a patterned actuator $\left(5 \times 25 \mathrm{~mm}^{2}, 40 \%\right.$ coverage, and $90 \mu \mathrm{m}$ of an LCE on PEI, Figure 2b). (a) Edge-on images of the film at different temperatures. The blue dashed lines represent the shape of the film at $25{ }^{\circ} \mathrm{C}$. Scale bar represents $1 \mathrm{~mm}$. (b) Edge-on images displaying the light-driven bending motion of the patterned film to $365 \mathrm{~nm}\left(80 \mathrm{~mW} \mathrm{~cm}{ }^{-2}\right)$ and $455 \mathrm{~nm}$ light $\left(145 \mathrm{~mW} \mathrm{~cm}^{-2}\right)$. (c) Tip displacement as a function of time. Positive values mean that the tip bent away from its starting position, that is, from the light source, and negative when bent toward the light.

as the trigger is appealing because it can be rapidly, tetherlessly, and locally applied. ${ }^{42}$

Here, we report on actuators intermediate to single- and bilayer films, with multifunctionality and a plurality of possible shape changes. These light-responsive-patterned actuators fabricated via direct ink writing (DIW) display several distinct, controlled deformation modes on demand. To establish the potential of locally depositing actuator material atop a passive substrate and to compare its performance to conventional fully covered substrates, a single LCE stripe is written on a polymer substrate and the device responsivities to both temperature and light are characterized. Interestingly, large deformations were triggered by both light and temperature but in opposing directions. These findings are used to fabricate actuators with multiple LCE stripes with different reversible and controlled shape deformations upon specific illumination of the different light-responsive regions. Additionally, partial coverage with an active material provides partial transparency to the actuator and space for applying additional layers, for example, photonic reflectors. In the latter case, we present an actuator capable of performing two tasks simultaneously: motion and selective reflection of different wavelengths of light.

\section{RESULTS AND DISCUSSION}

Generating Patterned Actuators. The patterned, lightresponsive LC actuators were prepared by DIW. The alignment of the LC mesogens, key to the actuator's eventual performance, is dictated by the DIW procedure (Figure 1). ${ }^{3}$ This fabrication approach permits the easy deposition of discrete, light-responsive regions that can be independently triggered. ${ }^{6}$ We selected a thin $(10 \mu \mathrm{m})$ uniaxially stretched polyetherimide (PEI) foil with nanogrooves as the passive substrate (Figure S1). There is no indication that stretched PEI acts as an alignment layer for oligomeric mesogens: alignment is solely dictated by the relative motion of the printing head to the substrate. PEI has a storage modulus of $c a$. $3000 \mathrm{MPa}$ at $20{ }^{\circ} \mathrm{C}$ (Figure 2a) on the same order of magnitude poly(ethylene terephthalate) (PET); ${ }^{21,23}$ it is transparent to blue light but not ultraviolet (UV) light.
The LC oligomer was synthesized via a base-catalyzed thiolacrylate Michael addition reaction of $1-3$ as previously reported $^{44}$ (Figure 1, the results of the different characterizations of the prepared oligomer may be found in Figures S2S4 and Tables S1 and S2 in the Supporting Informtation). The excess acrylate compared to thiol groups resulted in acrylateterminated oligomers with molecule $\mathbf{2}$ in the main chain; the azobenzene group is responsible for granting the network light responsivity with its photo-induced trans-to-cis isomerization. ${ }^{30}$ The synthesized oligomer had a number-average molecular weight $\left(M_{\mathrm{n}}\right)$ of $7756 \mathrm{~g} \mathrm{~mol}^{-1}$ based on the ${ }^{1} \mathrm{H}$ NMR spectrum, with a dispersity $(Ð)$ of 2.4 as determined using gel permeation chromatography (GPC), and showed an isotropic-to-nematic phase transition $\left(\mathrm{T}_{\mathrm{I} / \mathrm{N}}\right)$ at $80{ }^{\circ} \mathrm{C}$ and a nematic-to-smectic $\mathrm{C}$ $(\mathrm{N}-\mathrm{SmC})$ phase transition $\left(\mathrm{T}_{\mathrm{N} / \mathrm{SmC}}\right)$ of $42{ }^{\circ} \mathrm{C}$, as indicated by the differential scanning calorimetry (DSC) traces and crossed polarized light micrographs. The LC ink for the DIW process was prepared by mixing the LC oligomer (98 wt \%) with a photoinitiator (2 wt \% 4).

The patterning process on PEI foils was first optimized. The influence of the printing direction on the mesogenic alignment, either parallel or perpendicular to the stretching direction of the PEI, was investigated (Figure S5) with the reservoir set to $70{ }^{\circ} \mathrm{C}$ and the printing bed to $20{ }^{\circ} \mathrm{C}$. At these temperatures, printing at a speed of $7 \mathrm{~mm} \mathrm{~s}^{-1}$ with a $335 \mu \mathrm{m}$ diameter nozzle invariably resulted in uniaxially aligned lines, independent of the underlying PEI stretching direction. These results verify that the PEI foil is not acting as an alignment layer, and the mesogenic alignment is determined solely by the DIW process, as expected.

After printing, the formation of the LCE network was initiated using high-intensity UV light at room temperature under $\mathrm{N}_{2}$. Sol/gel fraction experiments revealed an average $85 \%$ gel fraction for the LCE. Copolymerization of acrylate groups generally results in higher fractional network formations, but the high viscosity and the long oligomeric chains (ca. 9 units) of this system reduce the mobility of the radicals and lower the cross-link density, respectively, resulting in a reduced gel fraction. 
With the printing parameters optimized, we deposited a single $2 \times 35 \mathrm{~mm}^{2}(w \times l)$ LCE stripe on a PEI foil $(10 \times 10 \times$ $\left.0.001 \mathrm{~cm}^{3}\right)$. After photopolymerization, a laser cutter was employed to extract a $5 \times 25 \mathrm{~mm}^{2}$ film with the LCE rectangle situated along the center of the PEI (Figure 2b). As a result, the PEI film had $40 \%$ of its area covered by the LCE. We observed that in some cases the films showed a prebend when suspended. We hypothesize that the prebend is a consequence of the high temperature experienced by the films during laser cutting because bare laser-cut PEI films having the same dimensions also showed prebends: a linear relationship between the prebend and laser intensity was observed (Figures S6 and S7). Furthermore, characterization of the patterned film revealed that the thickness of the deposited LCE averaged to $90 \mu \mathrm{m}$, as determined by an optical profiling system (Figure $2 c)$. Across the $3 \mathrm{D}$ profile, the active area shows an undulating topography, with each "wave" representing one of the deposited filaments that constitute the LCE stripe. The birefringence of the active layer was observed between crossed polarizers (Figure 2d): the LCE stripe appeared darker when oriented parallel to the polarizer or analyzer than when at $45^{\circ}$. This dark-bright state indicates a uniaxially oriented LCE: ${ }^{3}$ in this case, the mesogenic alignment was parallel to the longitudinal axis.

Temperature Response. The response of the $5 \times 25$ $\mathrm{mm}^{2}, 40 \%$ covered, and $90 \mu \mathrm{m}$ LCE film (Figure $2 \mathrm{~b}$ ) to temperature was evaluated (Figure $3 \mathrm{a}$ ). Upon increasing the temperature from 25 to $110{ }^{\circ} \mathrm{C}$, the film initially bent, and then started to tightly roll up above $80{ }^{\circ} \mathrm{C}$, with the LCE inside the curvature. Such a response is not surprising as uniaxially aligned LCEs are known to display large, anisotropic shape deformations ( $c$ a. 50\%), ${ }^{3,16}$ contracting along and expanding perpendicular to the alignment direction (Figure S8). The temperature response arises from the increasing disorder of the mesogenic groups with increasing temperature as the network undergoes phase transitions. Upon heating, the network transitions from the SmC-to- $\mathrm{N}$ phase around $45{ }^{\circ} \mathrm{C}$, and from the $\mathrm{N}$-to-isotropic phase around $94{ }^{\circ} \mathrm{C}$ (Figure S9), explaining the two stages of the response seen both in Figure 3a and in Figure S8. Bare PEI itself does not show any shape changes within the evaluated temperature range (Figures S8 and S10). Hence, as previously observed for bilayers, when one of the layers experiences a contraction or expansion along the longitudinal axis, the system bends parallel or perpendicular to it, respectively. ${ }^{45}$ Thanks to the large contraction of LCEs, the film's final configuration is a tight roll. In comparison, highly cross-linked LC network (LCN) bilayer films (LCNs characteristically having $10 \%$ contraction due to their higher crosslink density) ${ }^{3,16}$ typically only bend up to a full rotation, ${ }^{18}$ and generally do not tightly roll up unless they have a wedge geometry. ${ }^{46}$

Light Response. Photoactuation of a patterned actuator can be characterized either in air or underwater because the chosen LCE performs in either of these media. ${ }^{44}$ Systematic studies of the photoactuation in air can be difficult, as both photomechanical and photothermal effects influence the actuation (Figures S11 and S14); ${ }^{47}$ consequently, the light response was investigated underwater where photomechanical effects dominate. The $5 \times 25 \mathrm{~mm}^{2}, 40 \%$ covered, and $90 \mu \mathrm{m}$ LCE-patterned film (Figure $2 \mathrm{~b}$ ) was suspended in $19{ }^{\circ} \mathrm{C}$ water as shown in Figure S11: at this temperature, the LCE is in its SmC phase. When irradiated with a $365 \mathrm{~nm}$ light emitting diode (LED) $\left(80 \mathrm{~mW} \mathrm{~cm}^{-2}\right)$, the film bent away from the light source (Figure 3b and Movie S1), an expected performance for this LCE. The bending away motion is the result of a photoinduced SmC-to-smectic A (SmC-SmA) phase transition and ca. $4 \%$ expansion parallel to the alignment direction. ${ }^{44} \mathrm{~A}$ stationary state was attained after $10 \mathrm{~min}$ of illumination, after which the light was switched off. Because of the photomechanical nature of the response, the deformation was only reversed when illuminated with a $455 \mathrm{~nm}$ LED (145 mW $\mathrm{cm}^{-2}$ ), which induced the back isomerization from cis to trans (Figure 3c). This bending motion was reversible for at least 12 cycles with no apparent signs of fatigue (Figure S15). Additionally, no delamination of the LCE from the PEI was observed after the 12 cycles, suggesting good adhesion of the stripe to the passive substrate. Despite being only $40 \%$ covered with the light-responsive LCE, the film showed a large, lightdriven deformation, with a maximum tip displacement of 25 $\mathrm{mm}$. A similar performance was observed for a film with the stretching direction of the PEI foil perpendicular to the printing direction rather than parallel (Figure S15). The observed tip displacement is comparable to the displacement of a single-layer film made from the same $\mathrm{LCE}^{44}$ and to other single- and bilayer films having similar dimensions with $100 \%$ surface area coverage, where maximum light-driven deformations are ranged from 18 to $26 \mathrm{~mm} .{ }^{5,21,23,43,47}$ This result suggests that large deformation can be obtained without fully covering the passive layer with an active material, inspiring new designs of actuators to unlock their full potential.

Influence of Thickness, Shape, and Coverage on the Photoactuation. There are three tunable parameters in the patterned actuator: the thickness of the active LCE $\left(t_{\mathrm{LC}}\right)$, fractional coverage of the passive PEI, and aspect ratio of the film. The effect of each variable on the maximum tip displacement was systematically studied, see Tables S3-S5.

The influence of the thickness of the active LCE pattern, $t_{\mathrm{LC}}$, on photoactuation was investigated in a series of films in which the dimensions $\left(5 \times 25 \mathrm{~mm}^{2}\right)$ and fractional coverage $(40 \%)$ of the passive PEI layer were kept constant (Figure S16 and Table S3). Upon increasing $t_{\mathrm{LC}}$ from $50 \mu \mathrm{m}$ to $150 \mu \mathrm{m}$, the maximum tip displacement recorded after $10 \mathrm{~min}$ of illumination with $365 \mathrm{~nm}$ light increased consistently until it reached a maximum value at a thickness of $95 \mu \mathrm{m}$, at which point it decreased. Preliminary simulations are consistent with this experimental data (Figure S17) and reveal the importance of the illumination conditions. When the active layer is illuminated, two regions are formed through the depth of the LCE: (1) an exposed region at the surface that expands along the longitudinal axis and (2) the nonexposed, deeper region that remains inert. The extent of the expanding region depends on several factors (including illumination time, light intensity, and azobenzene concentration). In thin LCE layers, the entire depth of the LCE stripe is exposed to the light, causing for its entirety to expand. A further increase of $t_{\mathrm{LC}}$ results in unexposed regions within the LCE that increase the effective bending stiffness of the actuator, reducing the maximum tip displacement, which is inversely correlated to the passive layer thickness cubed $\left(t^{3}\right) .{ }^{43}$ The resulting optimal thickness value for the LCE for maximum tip displacement is, thus, determined by our specific illumination conditions.

We investigated the effect of varying fractional coverage in the photoactuation in a series of films with identical dimensions $\left(5 \times 25 \mathrm{~mm}^{2}\right)$ and deposited LCE thicknesses $(90 \mu \mathrm{m})$ (Figure $4 \mathrm{a}$ and Table S4). By increasing coverage from 0 to $100 \%$, the maximum tip displacement plateaued at 
(a)

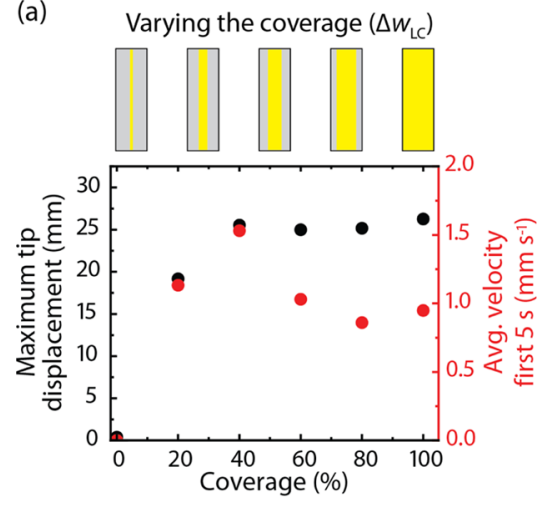

(b) Varying the aspect ratio $(\Delta w)$

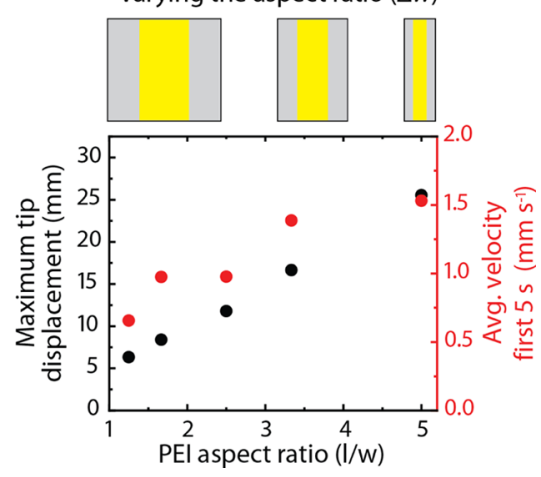

Figure 4. Maximum tip displacement and average velocity after $5 \mathrm{~s}$ of illumination as a function of (a) fractional LCE coverage and (b) PEI aspect ratio of the films with $40 \%$ LCE coverage, respectively. In both cases the illumination time with a $365 \mathrm{~nm}\left(80 \mathrm{~mW} \mathrm{~cm}^{-2}\right)$ LED was $10 \mathrm{~min}$. Above the plots, schematics represent some of the films used for the studies. Yellow indicates the LCE and light gray represents the PEI. In Tables S4 and S5 from the Supporting Informtation the reader can find the different dimensions, thickness, and prebends of the films used for this optimization study. ca. $40 \%$ coverage. The comparative rate of actuation during the initial 5 s of light exposure was roughly linear until $40 \%$ coverage where it peaks and roughly plateauing at greater coverages. Preliminary simulations were generally consistent with the experimental data and help in understanding the observed tendencies (Figure S17). It appears that a minimum coverage is required to initiate rapid, extensive actuation: the degree of coverage required will be affected by the relative physical characteristics of the passive and active layers and the illumination conditions. When increasing the fractional coverage of the LCE, the width of the stripe increases, resulting in increasingly significant perpendicular contraction and the generation of orthogonal stresses that oppose tip displacement, contributing to the plateau formation for displacement and decay in the absolute velocity. The orthogonal stresses that oppose tip displacement arise from the illuminated region as it expands parallel to the alignment (ca. $4 \%),{ }^{44}$ but it also contracts perpendicular to it (ca. $2 \%$, see Supporting Informtation for the calculations). Thus, the $c a$. $40 \%$ covered soft actuator outperforms $100 \%$ covered actuators with respect to speed, while the maximum tip displacement is about the same; this is an important finding to consider in future designs of patterned actuators, as it suggests less material is actually better.

Finally, the effect of the patterned actuator aspect ratio on photoactuation was evaluated. The widths $(w)$ of the films were increased while maintaining $25 \mathrm{~mm}$ length, fractional coverage $(40 \%)$, and thickness $(90 \mu \mathrm{m})$ (Figure $4 \mathrm{~b}$ and Table S5). By increasing the aspect ratio from 1.3 to 5 , the maximum tip displacement and the average speed for the first $5 \mathrm{~s}$ of illumination increased linearly. When increasing the aspect ratio, the width of the LCE layer $\left(w_{\mathrm{LCE}}\right)$ is proportionally reduced. As a result, the ca. $2 \%$ contraction that occurs along $w_{\mathrm{LCE}}$ that induces the bending opposing the tip displacement is minimized, but the expansion (ca. 4\%) along the longitudinal (a)

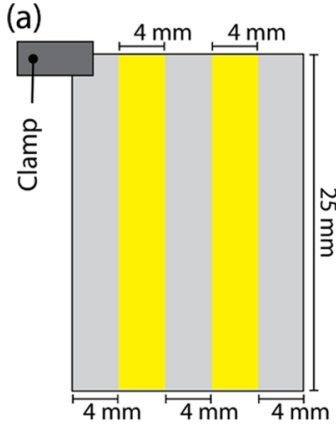

(b)

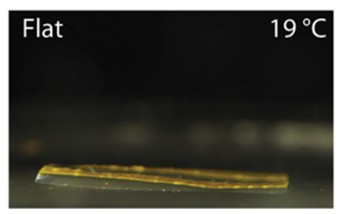

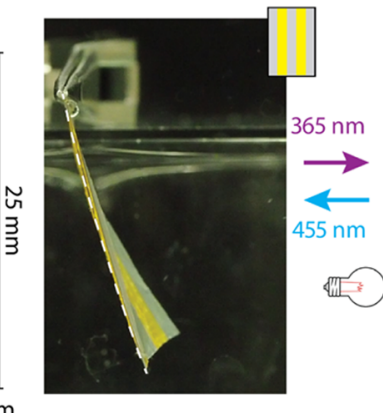
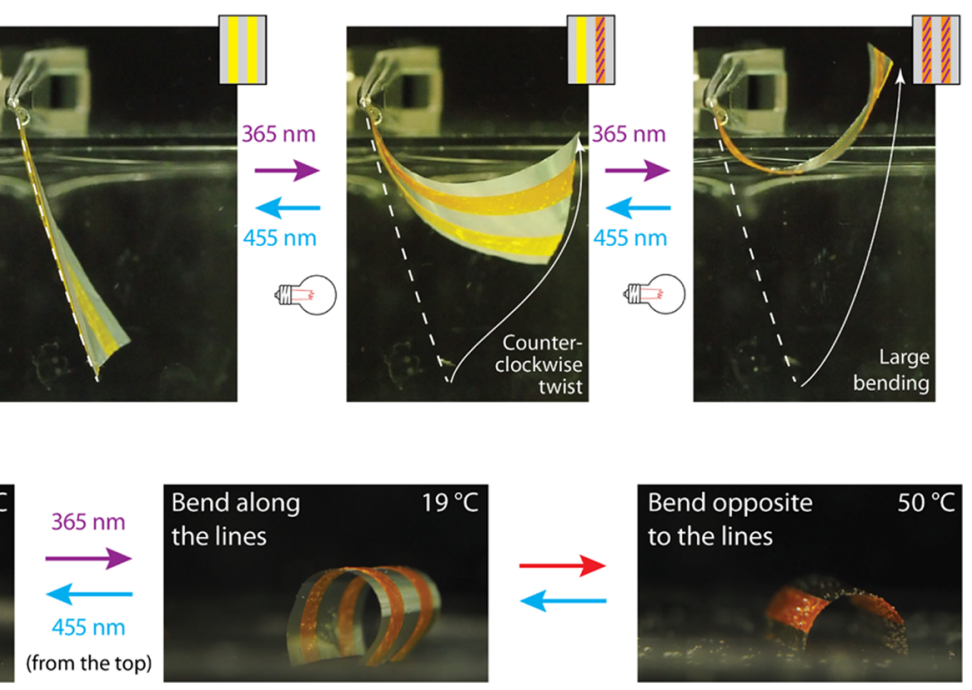

Figure 5. Underwater performance of an actuator presenting multiple shape changes. (a) On the left, a schematic drawing of the actuator: yellow indicates the LCE and light gray represents the PEI. The thickness of the LCE was found to be $90 \mu \mathrm{m}$. On the right, edge-on photographs of the actuator showing the different deformations accomplished when illuminated, partially or completely, with a $365 \mathrm{~nm}\left(80 \mathrm{~mW} \mathrm{~cm}{ }^{-2}\right)$ LED. The insets show which region of the actuator is illuminated in each case; the active part has been patterned with purple lines and colored in orange. (b) Series of images showing the deformations that the actuator from (a) undergoes when no constraints are applied and light (from the top) and temperature are used to trigger different stresses and induce phase changes in the active layer that result in bending in opposite directions. Detailed snapshots of the shape changes from 19 to $50{ }^{\circ} \mathrm{C}$ can be found in Figure S20. For both (a,b), snapshots of the simulated actuation can be seen in Figure S18. 
(a)

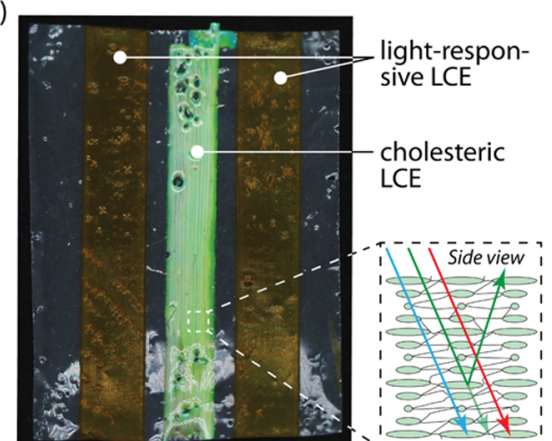

(d)

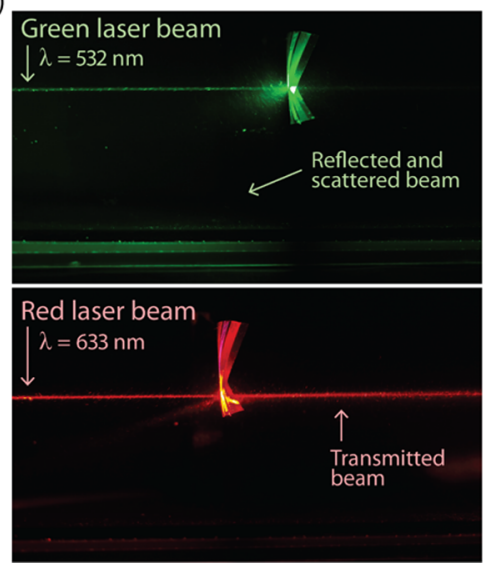

(b) 100

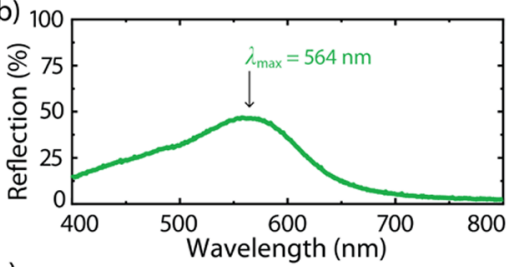

(c)

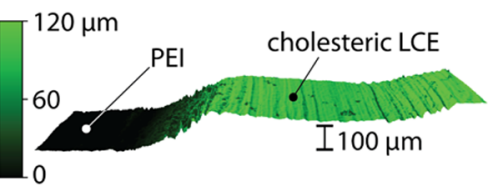

$35 \mathrm{~mm}$

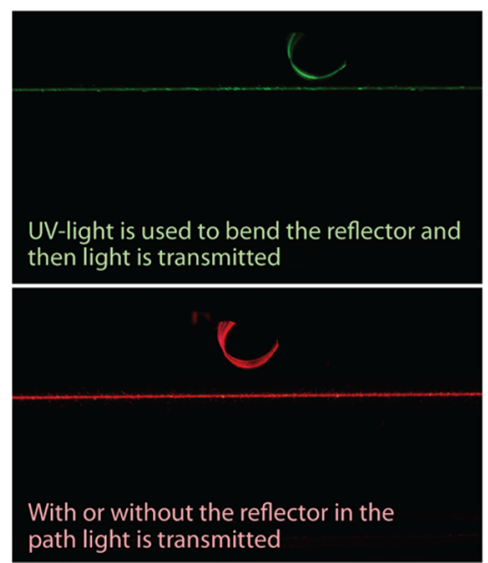

Figure 6. Light-responsive photonic actuator. (a) Front photograph of the light-responsive photonic actuator. The inset shows the molecular alignment of the CLCE line, which consist of a helix structure. Thanks to the periodicity of the full rotation of the helix, around 376 nm, the middle line acts as the reflector for green light. (b) Fraction of reflected light as a function of the incident wavelength on the CLCE. (c) 3D profile of the edge of the CLCE and the PEI. (d) Series of edge-on photographs in which the selectivity to reflect a specific wavelength of the actuator and lightdriven deformation are shown. The images show the actuator underwater. The $365 \mathrm{~nm}\left(80 \mathrm{~mW} \mathrm{~cm}^{-2}\right), 455 \mathrm{~nm}\left(145 \mathrm{~mW} \mathrm{~cm}^{-2}\right)$, and laser lights were all incident from the left.

axis responsible for the bending is maintained, as the length is not altered. Thus, increasing the aspect ratio results in larger and faster actuations as the forces opposing bending are reduced.

Patterned Actuators with Various Shape-Morphing Capabilities. To fully explore the potential of patterning, a 20 $\times 25 \mathrm{~mm}^{2}$ film topped by two $4 \times 25 \mathrm{~mm}^{2}$ stripes of the LCE separated by $4 \mathrm{~mm}$ was fabricated (Figure 5a and Movie S2). The film has $40 \%$ of the PEI foil covered by the LCE and an aspect ratio of 1.3. Each of the two active layers can be individually triggered thanks to the space between them. Triggering one or the other of the LCE stripes by continual exposure up and down the stripe results in a twisting motion either counter-clockwise or clockwise, depending on which stripe is activated. Thus, by the simple printing of two stripes, additional motions can be induced in the film, also predicted by simulation (Figure S18). Interestingly, when both stripes are irradiated simultaneously, the film bends, with the bend significantly greater than for a film having an identical net aspect ratio and total coverage fraction (40\%), but with the active region concentrated as a single stripe in the center (Figure S19 and Movies S3 and S4). Such performance enhancements suggest that the active layer's distribution should also be considered when designing patterned actuators. We hypothesize that this increased amplitude response is the result of reducing the aspect ratio of the active layer, minimizing the counteracting forces from the perpendicular expansion of the LCE stripe.
The light response of the LCE used here has a unique temperature sensitivity which controls the directionality of the light-driven bending motion, ${ }^{44}$ as demonstrated when actuating the films in air at different light intensities (Figures S13 and S14). Basically, when the network is illuminated in the $\mathrm{SmC}$ mesophase, it bends away from the light, while when illuminated in the $\mathrm{N}$ mesophase, it bends toward the light source. We thus explored this property of the LCE to induce additional shape changes in patterned actuators $\left(2 \times 25 \mathrm{~mm}^{2}\right.$, $40 \%$ coverage, and $90 \mu \mathrm{m}$ of LCE, Figure 5a) by combining light and temperature (Figure $5 \mathrm{~b}$ ). Rather than being suspended, the film was left at $19{ }^{\circ} \mathrm{C}$ underwater, lying on the floor of the container with the LCE side facing upward. Upon light illumination from the top at $19{ }^{\circ} \mathrm{C}$, the film bent away from the light source and eventually ended up standing. The light was switched off, and the temperature gradually increased from 19 to $28{ }^{\circ} \mathrm{C}$ (Figure S20). Initially, the film started to unbend toward its initial flat state, which was expected as temperature induces a phase transition in the polymer network from Sm-to-N, resulting in a gradual contraction of the illuminated $\mathrm{LCE}^{44}$ parallel to an opposing anisotropic shape change induced by temperature in the unexposed region of the network (Figure S8). ${ }^{44}$ However, from 30 to $50{ }^{\circ} \mathrm{C}$, the film started to bend perpendicular to the longitudinal axis, increasing its curvature with temperature. Illumination with blue light had no effect on this deformation. Sudden removal from the water and placement on a $20{ }^{\circ} \mathrm{C}$ surface resulted in recovery of its initial bent state along the 
longitudinal axis. Placed again in water at $50{ }^{\circ} \mathrm{C}$, the film immediately switched its bending to opposite of the longitudinal axis instead of along it. Such orthogonal bending motion induced by a combination of light and temperature was also predicted by the simulations which supports the proposed mechanism behind this atypical shape change (Figure S18). This atypical perpendicular bending is the result of the temperature-induced LCE expansion occurring opposite to the alignment direction (Figure S8), when the LCE layer is spread as two stripes, as opposed to having it concentrated in a single stripe as in Figure 3, which results in such a unique motion. Thus, two stripes plus a combination of light and temperature led to a film that reversibly switches from flat to bent along the longitudinal axis to bending opposite to it, making this the first actuator showing such shape-morphing capability.

We also fabricated larger patterned actuators with alternative deformations modes. A $25 \times 36 \mathrm{~mm}^{2}, 33 \%$ covered, and $90 \mu \mathrm{m}$ LCE film with four separate LCE stripes (one pair of $4 \times 25$ $\mathrm{mm}$ and one pair of $2 \times 25 \mathrm{~mm}$ ) could be sequentially twisted by gradually activating the stripes one by one, from bottom to top (Figure S21 and Movie S5). Another $20 \times 25 \mathrm{~mm}^{2}, 16 \%$ covered, and $90 \mu \mathrm{m}$ LCE film with two asymmetrical LCE lines (one stripe of $1.7 \times 25 \mathrm{~mm}$ and one of $1.5 \times 25 \mathrm{~mm}$ ) resulted in different degrees of twist (Figure S22 and Movie S6). These examples embody the benefits of distributing the active material in discrete (symmetrical or asymmetrical) regions over the passive layer surface as it allows distinct, controlled, and reversible deformations modes.

Light-Responsive Photonic Actuator. The dual-stripe actuator presented in the previous section $\left(20 \times 25 \mathrm{~mm}^{2}, 40 \%\right.$ coverage, and $90 \mu \mathrm{m}$ of LCE, Figure 5a) left a significant fraction of the PEI foil uncovered. This construction allows for deposition of an additional functional ink in the blank regions. We opted to print a single $3 \times 24 \mathrm{~mm}^{2}$ stripe cholesteric LC (CLC) ink, a photonic polymer network with a helical arrangement of LC molecules, ${ }^{48}$ between the previously deposited light-responsive LCE stripes (Figure 6a). Optical and structural characterization of the $100 \mu \mathrm{m}$ thick reflective CLC layer shows a broad reflection band centered at $564 \mathrm{~nm}$ (Figure $6 b, c)$. The edges of the layer are less defined than those observed in Figure 2c, as the CLC ink has a lower viscosity than the LC ink, so after extrusion it shows increased spreading before polymerization. The difference in viscosity between the inks also explains the dewetting observed at the extremes of the reflective stripe. The film still displays large bending deformations triggered by light despite the addition of the extra CLC layer (Figure S22). The potential use as a dynamic reflector was investigated (Figure 6d). The lightresponsive-actuating reflector was suspended underwater and the CLC stripe exposed to light from green $(\lambda=532 \mathrm{~nm})$ or red $(\lambda=633 \mathrm{~nm})$ lasers. At rest, red light was transmitted while green light was partially reflected by the film, as expected (Figure 6b). $365 \mathrm{~nm}$ light was then used to trigger the responsive LCE in the stripes, causing film bending. As a result, the central reflective region was removed from the path of both lasers, permitting a light controlled on-and-off transmission of the green laser light through the water. This patterned actuator, having two stripes of a light-responsive material and one of a photonic elastomer, shows the benefit of patterning different materials to obtain multiple functionalities while having numerous shape-morphing capabilities in the same film.

\section{CONCLUSIONS}

We have demonstrated that using DIW to fabricate LC-based patterned films leads to actuators providing alternative, controlled shape deformations with additional functionalities possible. The systematic study performed in this work revealed that passive substrates, such as thermoplastics, can be made responsive without fully covering the surface with active material or affecting their performance, which reduces the fabrication cost as less of the expensive LC material is needed. Additionally, patterning offers the possibility of having discrete active regions of the foils that can be individually triggered and create localized stresses, similar to how tendons control motion in human hands. As a result, we could achieve reversible, lightdriven twisting, both right- and left-handed, and bending, parallel and perpendicular to one of the axes, in the same film. Additionally, partially covering the passive layer also allows a facile combination of different materials that have distinct functionalities. This was demonstrated by fabricating a photonic light-responsive actuator that could selectively reflect a specific wavelength on demand. The results discussed in this contribution embody the potential of using DIW in fabricating a new class of patterned actuators with expanded functionality and shape deformation capabilities. Now the mechanism behind the response of the present system is mostly understood, future research should make use of simulation to predict optimal patterns of an active material for fabricating soft actuators with novel functionalities, responsivities, and complex shape-morphing capabilities.

\section{EXPERIMENTAL SECTION}

Materials. 1,4-Bis-[4-(6-acryloyloxyhexyloxy) benzoyloxy]-2methylbenzene (1) was obtained from Merck. 4,4'-Bis(6-acryloyloxyhexyloxy) azobenzene (2) was acquired from Synthon. 2,2'(Ethylenedioxy)diethanethiol (3) and 1,8-diazabicyclo[5.4.0]undec7-ene (DBU) were purchased from Sigma-Aldrich. The photoinitiator bis(2,4,6-trimethylbenzoyl)-phenylphosphineoxide (4) was obtained from Ciba. The chiral dopant, $(3 R, 3 \mathrm{a} R, 6 S, 6 \mathrm{a} R)$-hexahydrofuro[3,2b] furan-3,6-diyl bis(4-((4-(((4-(acryloyloxy)butoxy) carbonyl)oxy)benzoyl)oxy)benzoate) (5) used to prepared the CLC ink was purchased from BASF SE, see Figure S23 for the molecular structure. 1,8-Diazabicyclo[5.4.0]undec-7-ene (6, DBU) and dimethylphenylphosphine $(7, \mathrm{Me} 2 \mathrm{PPh})$ were acquired from $\mathrm{TCl}$ Chemicals Europe N.V. Dichloromethane (DCM) was obtained from Biosolve. PEI foil (Ultem UTF 120) of $10 \pm 2 \mu \mathrm{m}$ thickness was supplied by SABIC.

Characterization. The number-average molecular weight, $M_{n}$, of the oligomers and their number-average repeating units value were obtained from ${ }^{1} \mathrm{H}$ NMR spectra performed using a $400 \mathrm{MHz}$ Bruker ADVANCE III HD spectrometer with deuterated chloroform as the solvent. A Shimadzu LC-2030.3D with $254 \mathrm{~nm}$ PDA and refractive index detectors was utilized to perform GPC to measure the weight average molecular weight $\left(M_{\mathrm{w}}\right)$ and dispersity, $Ð$, using polystyrene (PS) with an average $M_{\mathrm{w}}$ of $350,000 \mathrm{~g} \mathrm{~mol}^{-1}$ as the reference. The location of the (meso)phase and glass transitions were determined from DSC traces obtained using a TA Instruments DSC Q2000 at a cooling and heating rates of $10{ }^{\circ} \mathrm{C} \mathrm{min}-1$. The mechanical properties of freestanding PEI and LC films were measured using a TA Instruments Q800 dynamic mechanical analyzer (DMA). Storage moduli as a function of temperature $\left(5{ }^{\circ} \mathrm{C} \mathrm{min}^{-1} \mathrm{ramp}\right)$ were measured at a frequency $f=1 \mathrm{~Hz}$ with an amplitude set to $20 \mu \mathrm{m}$. Expansion coefficients were determined in controlled force $(10 \mathrm{mN})$ experiments in which the reversible changes in length were monitored as a function of temperature $\left(5^{\circ} \mathrm{C} \mathrm{min}{ }^{-1}\right.$ ramp $)$. Optical micrographs were recorded with a Leica DM $2700 \mathrm{M}$ polarized optical microscope equipped using a Leica MC170 HD camera. All structures were visualised in a bright field transmission mode. An optical profiling system (Sensofar S neox 3D Optical profiler, equipped with a $5 \times$ 
objective) was employed to record $3 \mathrm{D}$ profiles of the edges of the printed polymers to measure their thicknesses. UV-vis spectra were recorded using a PerkinElmer Lambda 750 spectrometer equipped with a $150 \mathrm{~mm}$ integrating sphere and a tungsten halogen light source for measurements between 320 and $850 \mathrm{~nm}$ light wavelengths. The samples were placed before the inlet of the integrating sphere for transmission and absorption measurement and at the back of the sphere for reflection measurements.

Preparation of the LC Ink. The LC oligomer was prepared as previously reported. ${ }^{44}$ The synthesis is based on a catalyzed thiolacrylate Michael addition reaction of diacrylate mesogen $\mathbf{1}$ and diacrylate azobenzene $\mathbf{2}$ using as a spacer $\mathbf{3}$. The acrylate-to-thiol ratio was set to 1.0:0.9 to obtain acrylate-terminated oligomers. The final concentration of azobenzene 2 was 7 wt \%. In short, first 1-3 are dissolved in DCM. Under constant agitation, a few drops of DBU (6) are added to the solution. The solution was left to react for at least $2 \mathrm{~h}$ and the oligomer was then washed with $1 \mathrm{M} \mathrm{HCl}(2 \times)$ and saturated brine $(1 \times)$ to remove the existing DBU. The organic phase was collected and dried with $\mathrm{MgSO}_{4}$ and the residual solvent was removed in a vacuum oven at $90{ }^{\circ} \mathrm{C}$ overnight. The characterization of the prepared LC oligomer can be found in Figures S1 and S2 and Tables S2 and S3. The LC ink was prepared by mixing the LC oligomer (98 wt \%) with the photoinitiator (2 wt \% 4) in DCM. After complete dissolution of the components, the LC ink was obtained by removing the solvent by casting the solution in a Teflon Petri dish and leaving it at room temperature under vacuum overnight.

Preparation of the CLC Ink. The photonic CLC ink was prepared as previously described. ${ }^{48}$ In short, the CLC ink was prepared via a nucleophile catalyzed thiol-acrylate Michael addition. Here, the molar ratio of diacrylate-to-dithiol was 3:2. The final concentration of chiral dopant was 5.7 wt \% 5 (Figure S23). After dissolving all components in DCM at room temperature, catalyst 7 was added and the reaction was left under strong stirring for $1 \mathrm{~h}$. The CLC ink was prepared by mixing the CLC oligomer (98 wt \%) with the photoinitiator $(2 \mathrm{wt} \% 4)$ in DCM. The solvent was removed at room temperature overnight under vacuum.

Direct Ink Writing. Controlled depositions of the inks on the 10 $\mu \mathrm{m}$ thick PEI foil was performed using a commercial 3D printer (EHR, Hyrel 3D). The inks were loaded at room temperature into a stainless steel reservoir with a $335 \mu \mathrm{m}$ nozzle diameter (27 ga A.W.G, Fisnar QuantX Micron-S Red). Uniaxial alignment for the LC ink was obtained by printing at a speed of $7 \mathrm{~mm} \mathrm{~s}^{-1}$ with the syringe at $70{ }^{\circ} \mathrm{C}$ and the bed at room temperature. To obtain cholesteric lines from the CLC ink, the optimal printing conditions were found by printing at 2 $\mathrm{mm} \mathrm{s}^{-1}$ with the syringe at $90^{\circ} \mathrm{C}$ and the bed at $53^{\circ} \mathrm{C}$, as previously reported. ${ }^{48}$ The LC ink requires high printing speeds to induce uniaxial alignment while the CLC ink needs low speeds and elevated temperature of the bed to facilitate the self-organization of the cholesteric alignment. ${ }^{44,48}$ The G-code that controlled the printing path was generated using printer software. After printing, photopolymerization was induced under inert conditions $\left(\mathrm{N}_{2}\right)$ using an Excelitas EXFO Omnicure S2000 light source in which 57\% of the light output has a wavelength of $395-445 \mathrm{~nm}$ and $43 \%$, of $320-390$ $\mathrm{nm}$. For samples containing azobenzene (2), an optical high-pass filter $(>405 \mathrm{~nm})$ was employed to avoid undesired isomerization. Exposure took place over $2 \mathrm{~h}$, the films being flipped every $30 \mathrm{~min}$ to circumvent a gradient forming in the cross-link density through the printed stripes thickness. ${ }^{44}$ Polymerization for the CLC stripe took place in $30 \mathrm{~min}$. The difference in the polymerization time of the two inks arises from the different viscosities (effecting the mobility of freeradicals), cross-link densities (effecting the probability for cross-links to form), and filter use (lowering the maximum light intensity available throughout the material). After fabrication, the optical properties, thicknesses, and alignments of the printed stripes were characterized using UV-vis spectroscopy, a 3D profiling system, and an optical microscope, respectively.

Gel Fraction. The fraction of cross-linking of the LCE network is defined as the gel fraction. To measure, a film was immersed in DCM for $24 \mathrm{~h}$ at room temperature. The sample was filtered and dried at 60 ${ }^{\circ} \mathrm{C}$ in a vacuum oven. The fraction of gel in the network was determined using eq 1 , in which $m_{\text {initial }}$ is the mass of the film before immersion in DCM and $m_{\text {dry }}$ is the mass of the film after filtration and subsequent drying.

Gel fraction $=\left(m_{\text {dry }} / m_{\text {initial }}\right) 100 \%$

Laser Cutting. Cuts of the PEI foil and on the LCE were performed using a laser cutter (Universal Laser Systems VLS 3.50, VersaLASER). The cutter is equipped with a $\mathrm{CO}_{2}$ laser beam with a power of up to $40 \mathrm{~W}$. The actual intensity encountered by the sample depends on the scanning speed (set at $80 \%$ ), dots per inch (set to $500)$, the focus $(0.1 \mathrm{~mm}$ above the sample holder), material absorbance, and the cleanness of the equipment. As a result, the laser power is difficult to reproduce from day-to-day, and so before every cutting session the optimal laser power was determined. All samples in which actuations were compared were cut the same day. The cutting path used to slice the samples was defined using AutoCAD software (Autodesk). The high temperatures created during cutting appear to induce a prebend in the samples, even in bare PEI foil samples, see Figures S6 and S7.

Underwater Photoactuation of the Actuators. The films, either suspended or laying on the floor of the container, were located inside a transparent container with flat sides filled with water. UV light (365 nm, Thorlabs M365L2) and blue light (455 nm, Thorlabs M455L3-C2) were used to switch between the two isomerization states of the azobenzene groups. For further details on the setup see Figure S11 from the Supporting Information. The light intensity was adjusted using a Thorlabs DC4104 controller. Before beginning the actual study, the samples were actuated for at least a couple of cycles to verify the reversibility and reproducibility of their shape changes and then illuminated with $455 \mathrm{~nm}$ light for at least $10 \mathrm{~min}$ to ensure all azobenzene groups were in the trans isomer. The light driven motion was recorded using a camera (Olympus OM-D E-M10 Mk III). The temperature of water was controlled with a digital thermometer: unless specified, its temperature was $19{ }^{\circ} \mathrm{C}$. The tip displacement of the patterned actuators was analyzed using Image J software. ${ }^{49}$ When investigating the selectivity of the printed CLCE to reflect certain wavelengths, green $(\lambda=532 \mathrm{~nm},<1 \mathrm{~mW}$, BASETech) and red ( $\lambda=633 \mathrm{~nm},<4 \mathrm{~mW}$, JDS Uniphase) lasers were employed.

Simulations. The temporal light-actuated coupled photomechanical response of the LCE/PEI bilayer actuators is simulated using an implicit dynamic solution procedure in commercial finite element software, ABAQUS. ${ }^{50}$ The two regions of LCE/PEI and PEI alone are created using partitions. The LCE/PEI region is modeled as a bilayer composite shell, whereas the PEI region is modeled as a homogenous shell. A total of 399 points are taken through the thickness to depict the through-thickness variation of cis mass fraction. The film is discretized using 4-node shell elements with reduced integration (S4R) with a mesh size of $0.2 \mathrm{~mm}$ for all the simulations. The different attenuation depths of trans and cis isomers and the corresponding influence on the attenuation of light through the thickness are considered to estimate the temporal evolution of the cis mass fraction through the thickness of the LCE accurately. The readers may refer to our earlier works ${ }^{51,52}$ for details on the photoisomerization model. The photo-isomerization parameters, ${ }^{51}$ namely, forward reaction coefficient $(\alpha)$, backward reaction coefficient $(\beta)$, trans attenuation depth $\left(d_{\mathrm{t}}\right)$, cis attenuation depth $\left(d_{c}\right)$, and thermal relaxation time constant $(\tau)$ are taken as reported in Table S6. The values of $d_{\mathrm{t}}$ and $d_{\mathrm{c}}$ are estimated from the absorption characteristics of the trans and cis isomers shown in Figure S3g. In the model, the influence of varying the angle between the light propagation direction and the director orientation $(\phi)$ on the isomerization kinetics as the film bends is considered by changing the polarization coefficient, $\zeta=$ $(1 / 3)\left(1-S P_{2}(\cos \phi)\right)\left(\right.$ where $\left.P_{2}(x)=\left(3 x^{2}-1\right) / 2\right)$, accordingly. The shadowing of some areas of the film as the film bends is also considered in the model. The elastic properties of the LCE and PEI are taken as mentioned in Table S6. Note that the elastic modulus of the LCE, PEI, and the photo-isomerization parameters $(\alpha, \beta$, and $\tau)$ strongly influence the temporal response and the magnitude of the tip displacement. The photo-expansion coefficients for the LCE in the 
$\mathrm{SmC}$ phase are taken following the $\mathrm{X}$-ray scattering measurements as discussed in the Supporting Information. The thermal expansion coefficients are taken from the experimental measurements (see Figure S8). To simulate the combined light- and heat-actuated response, that is, the influence of phase transition SmC-N, on the deformation, the photo-expansion coefficients are varied as a function of temperature linearly between the pure $\mathrm{SmC}$ phase (assumed to be at $19{ }^{\circ} \mathrm{C}$ ) and pure $\mathrm{N}$ phase (assumed to be at $50{ }^{\circ} \mathrm{C}$ ).

\section{ASSOCIATED CONTENT}

\section{SI Supporting Information}

The Supporting Information is available free of charge at https://pubs.acs.org/doi/10.1021/acsami.1c20348.

PEI foil characterization; LC ink characterization; lifetime of the cis-isomer; laser cutting studies; DMTA characterization of the PEI and LCE film; photoactuation in air and extra photoactuation underwater; dimensions on the sample; schematic of the chiral dopant employed to prepare the CLC ink; parameters for the computational models; calculation for the lightinduced anisotropic expansion/contraction; dimension for the actuators fabricated for the optimization of the photoactuation; schematic of the setup employed for the characterization of the photoactuation; and effect of PEI on the alignment of the deposited LCE (PDF)

Underwater photoactuation of a hanging-patterned film $\left(5 \times 25 \mathrm{~mm}^{2}, 40 \%\right.$ covered, $90 \mu \mathrm{m}$ LCE) having one stripe (MP4)

Underwater photoactuation of a hanging-patterned film $\left(20 \times 25 \mathrm{~mm}^{2}, 40 \%\right.$ covered, $90 \mu \mathrm{m}$ LCE $)$ having two stripes (MP4)

Underwater photoactuation of a patterned film $(20 \times 25$ $\mathrm{mm}^{2}, 40 \%$ covered, $90 \mu \mathrm{m}$ LCE) having one stripe (MP4)

Underwater photoactuation of a patterned film $(20 \times 25$ $\mathrm{mm}^{2}, 40 \%$ covered, $90 \mu \mathrm{m}$ LCE) having two stripes (MP4)

Underwater photoactuation of a hanging-patterned film $\left(25 \times 36 \mathrm{~mm}^{2}, 33 \%\right.$ covered, $90 \mu \mathrm{m}$ LCE) having four stripes (MP4)

Underwater photoactuation of a hanging-patterned film $\left(20 \times 25 \mathrm{~mm}^{2}, 16 \%\right.$ covered, $90 \mu \mathrm{m}$ LCE $)$ having two asymmetrical stripes (MP4)

\section{AUTHOR INFORMATION}

\section{Corresponding Authors}

Albert P. H. J. Schenning - Laboratory for Stimuli-responsive Functional Materials \& Devices (SFD), Department of Chemical Engineering and Chemistry, Eindhoven University of Technology (TU/e), $5600 \mathrm{MB}$ Eindhoven, The Netherlands; (1) orcid.org/0000-0002-3485-1984; Email: a.p.h.j.schenning@tue.nl

Michael G. Debije - Laboratory for Stimuli-responsive Functional Materials \& Devices (SFD), Department of Chemical Engineering and Chemistry, Eindhoven University of Technology (TU/e), $5600 \mathrm{MB}$ Eindhoven, The Netherlands; (1) orcid.org/0000-0001-8844-1115; Email: m.g.debije@tue.nl

\section{Authors}

Marc del Pozo - Laboratory for Stimuli-responsive Functional Materials \& Devices (SFD), Department of Chemical
Engineering and Chemistry, Eindhoven University of Technology (TU/e), 5600 MB Eindhoven, The Netherlands Jeroen A. H. P. Sol - Laboratory for Stimuli-responsive Functional Materials \& Devices (SFD), Department of Chemical Engineering and Chemistry, Eindhoven University of Technology (TU/e), $5600 \mathrm{MB}$ Eindhoven, The Netherlands; (1) orcid.org/0000-0002-1666-8502

Stefan H. P. van Uden - Laboratory for Stimuli-responsive Functional Materials \& Devices (SFD), Department of Chemical Engineering and Chemistry, Eindhoven University of Technology (TU/e), $5600 \mathrm{MB}$ Eindhoven, The Netherlands

Akhil R. Peeketi - Center for Responsive Soft Matter, Department of Mechanical Engineering, Indian Institute of Technology Madras, Chennai 600036, India

Sean J. D. Lugger - Laboratory for Stimuli-responsive Functional Materials \& Devices (SFD), Department of Chemical Engineering and Chemistry, Eindhoven University of Technology (TU/e), $5600 \mathrm{MB}$ Eindhoven, The Netherlands; (1) orcid.org/0000-0002-5215-1113

Ratna K. Annabattula - Center for Responsive Soft Matter, Department of Mechanical Engineering, Indian Institute of Technology Madras, Chennai 600036, India; (1) orcid.org/ 0000-0002-9492-8592

Complete contact information is available at: https://pubs.acs.org/10.1021/acsami.1c20348

\section{Author Contributions}

M.P., S.H.P.U, A.P.H.J.S., and M.G.D. designed the study. M.P., S.H.P.U, and J.A.H.P.S. synthesized the samples and performed sample analysis. S.J.D.L. performed dynamic mechanical measurements and discussed some of the experimental designs. A.R.P. and R.K.A. carried out the computational work. M.P., A.R.P., R.K.A., A.P.H.J.S., and M.G.D. interpreted experimental and computational results. M.P., A.P.H.J.S., and M.G.D. wrote the manuscript with revisions by all authors.

\section{Funding}

M.P., J.A.H.P.S., A.P.H.J.S., and M.G.D thank the funding by the Dutch Research Council (NWO) in the framework of the Innovation Fund Chemistry and from the Dutch Ministry of Economic Affairs and Climate Policy in the framework of the PPP allowance. R.K.A. gratefully acknowledges the financial support from the Science and Engineering Research Board, India, through a core research grant: CRG/2018/002365 and the generous financial support from IIT Madras under the Institutes of Eminence (IoE) scheme funded by the Ministry of Education, Government of India. A.R.P. acknowledges the financial support through Prime Minister's Research Fellowship for conducting doctoral research at IIT Madras.

\section{Notes}

The authors declare no competing financial interest.

\section{ACKNOWLEDGMENTS}

M.P., J.A.H.P.S., A.P.H.J.S., and M.G.D. extend their gratitude toward our project partners in the DynAM project consortium ("Dynamic Materials for Additive Manufacturing"). The authors thank N. Grossiord from SABIC for providing the PEI foils, D. C. Hoekstra for performing the GPC measurements, and S. Fredrich for cutting the samples using a laser cutter. Finally, we are grateful to T. A. P. Engels for useful discussions regarding experimental results. 


\section{ABBREVIATIONS}

LC, liquid crystal

LCE, liquid crystal elastomer

DIW, direct ink writing

PEI, polyethylenimine

PMDS, polydimethylsiloxane

PET, polyethylene terephthalate

$Ð$, dispersity

GPC, gel permeation chromatography

I, isotropic

$\mathrm{N}$, nematic

SmC, smectic C

SmA, smectic A

$T_{\mathrm{I} / \mathrm{N}}$, isotropic-to-nematic phase transition

$\mathrm{N}$-SmC, nematic-to-smectic C

$T_{\mathrm{N} / \mathrm{smC}}$, nematic-to-smectic $\mathrm{C}$ phase transition

DSC, differential scanning calorimetry

UV, ultraviolet

$\mathrm{P}$, polarizer

A, analyzer

LCN, liquid crystal network

LED, light emitting diode

CLC, cholesteric liquid crystal

PS, polystyrene

DMA, dynamic mechanical analysis.

DCM, dichloromethane

\section{REFERENCES}

(1) Sydney Gladman, A.; Matsumoto, E. A.; Nuzzo, R. G.; Mahadevan, L.; Lewis, J. A. Biomimetic 4D Printing. Nat. Mater. 2016, 15, 413-418.

(2) McCracken, J. M.; Donovan, B. R.; White, T. J. Materials as Machines. Adv. Mater. 2020, 32, 1906564.

(3) del Pozo, M.; Sol, J. A. H. P.; Schenning, A. P. H. J.; Debije, M. G. 4D Printing of Liquid Crystals: What's Right for Me? Adv. Mater. 2021, 2104390.

(4) Rich, S. I.; Wood, R. J.; Majidi, C. Untethered Soft Robotics. Nat. Electron. 201812 2018, 1, 102-112.

(5) Pilz da Cunha, M.; Kandail, H. S.; den Toonder, J. M. J.; Schenning, A. P. H. J.; Toonder, J. M. J. den; Schenning, A. P. H. J. An Artificial Aquatic Polyp That Wirelessly Attracts, Grasps, and Releases Objects. Proc. Natl. Acad. Sci. 2020, 117, 17571-17577.

(6) López-Valdeolivas, M.; Liu, D.; Broer, D. J.; Sánchez-Somolinos, C. 4D Printed Actuators with Soft-Robotic Functions. Macromol. Rapid Commun. 2018, 39, 1700710.

(7) Lee, Y.; Song, W. J.; Sun, J.-Y. Hydrogel Soft Robotics. Mater. Today Phys. 2020, 15, 100258.

(8) Wani, O. M.; Zeng, H.; Priimagi, A. A Light-Driven Artificial Flytrap. Nat. Commun. 2017, 8, 1-7.

(9) Huang, C.; Lv, J.-a.; Tian, X.; Wang, Y.; Yu, Y.; Liu, J. Miniaturized Swimming Soft Robot with Complex Movement Actuated and Controlled by Remote Light Signals. Sci. Rep. 2015, $5,1-8$.

(10) Kotikian, A.; McMahan, C.; Davidson, E. C.; Muhammad, J. M.; Weeks, R. D.; Daraio, C.; Lewis, J. A. Untethered Soft Robotic Matter with Passive Control of Shape Morphing and Propulsion. Sci. Rob. 2019, 4, No. eaax7044.

(11) Kotikian, A.; Truby, R. L.; Boley, J. W.; White, T. J.; Lewis, J. A. 3D Printing of Liquid Crystal Elastomeric Actuators with Spatially Programed Nematic Order. Adv. Mater. 2018, 30, 1706164.

(12) Ambulo, C. P.; Ford, M. J.; Searles, K.; Majidi, C.; Ware, T. H. 4D-Printable Liquid Metal-Liquid Crystal Elastomer Composites. ACS Appl. Mater. Interfaces 2021, 13, 12805-12813.

(13) Ceamanos, L.; Kahveci, Z.; López-Valdeolivas, M.; Liu, D.; Broer, D. J.; Sánchez-Somolinos, C. Four-Dimensional Printed Liquid Crystalline Elastomer Actuators with Fast Photoinduced Mechanical
Response toward Light-Driven Robotic Functions. ACS Appl. Mater. Interfaces 2020, 12, 44195-44204.

(14) del Barrio, J.; Sánchez-Somolinos, C. Light to Shape the Future: From Photolithography to 4D Printing. Adv. Opt. Mater. 2019, 7, 1900598.

(15) Liu, D.; Broer, D. J. Liquid Crystal Polymer Networks: Preparation, Properties, and Applications of Films with Patterned Molecular Alignment. Langmuir 2014, 30, 13499-13509.

(16) White, T. J.; Broer, D. J. Programmable and Adaptive Mechanics with Liquid Crystal Polymer Networks and Elastomers. Nat. Mater. 2015, 14, 1087-1098.

(17) Ambulo, C. P.; Burroughs, J. J.; Boothby, J. M.; Kim, H.; Shankar, M. R.; Ware, T. H. Four-Dimensional Printing of Liquid Crystal Elastomers. ACS Appl. Mater. Interfaces 2017, 9, 3733237339.

(18) Mol, G. N.; Harris, K. D.; Bastiaansen, C. W. M.; Broer, D. J. Thermo-Mechanical Responses of Liquid-Crystal Networks with a Splayed Molecular Organization. Adv. Funct. Mater. 2005, 15, 11551159.

(19) Verpaalen, R. C. P.; Debije, M. G.; Bastiaansen, C. W. M.; Halilović, H.; Engels, T. A. P.; Schenning, A. P. H. J. Programmable Helical Twisting in Oriented Humidity-Responsive Bilayer Films Generated by Spray-Coating of a Chiral Nematic Liquid Crystal. J. Mater. Chem. A 2018, 6, 17724-17729.

(20) Hagaman, D. E.; Leist, S.; Zhou, J.; Ji, H.-F. Photoactivated Polymeric Bilayer Actuators Fabricated via 3D Printing. ACS Appl. Mater. Interfaces 2018, 10, 27308-27315.

(21) Verpaalen, R. C. P.; Pilz da Cunha, M.; Engels, T. A. P.; Debije, M. G.; Schenning, A. P. H. J. Liquid Crystal Networks on Thermoplastics: Reprogrammable Photo-Responsive Actuators. Angew. Chem., Int. Ed. 2020, 59, 4532-4536.

(22) Boothby, J. M.; Ware, T. H. Dual-Responsive, Shape-Switching Bilayers Enabled by Liquid Crystal Elastomers. Soft Matter 2017, 13, 4349-4356.

(23) Pilz da Cunha, M.; Foelen, Y.; Raak, R. J. H.; Murphy, J. N.; Engels, T. A. P.; Debije, M. G.; Schenning, A. P. H. J. An Untethered Magnetic- and Light-Responsive Rotary Gripper: Shedding Light on Photoresponsive Liquid Crystal Actuators. Adv. Opt. Mater. 2019, 7, 1801643.

(24) Brannum, M. T.; Steele, A. M.; Venetos, M. C.; Korley, L. T. J.; Wnek, G. E.; White, T. J. Light Control with Liquid Crystalline Elastomers. Adv. Opt. Mater. 2019, 7, 1801683.

(25) Li, X.; Liu, J.; Li, D.; Huang, S.; Huang, K.; Zhang, X. Bioinspired Multi-Stimuli Responsive Actuators with Synergistic Color- and Morphing-Change Abilities. Adv. Sci. 2021, 8, 2101295.

(26) Fang, M.; Liu, T.; Xu, Y.; Jin, B.; Zheng, N.; Zhang, Y.; Zhao, Q.; Jia, Z.; Xie, T. Ultrafast Digital Fabrication of Designable Architectured Liquid Crystalline Elastomer. Adv. Mater. 2021, 2105597.

(27) Li, S.; Bai, H.; Liu, Z.; Zhang, X.; Huang, C.; Wiesner, L. W.; Silberstein, M.; Shepherd, R. F. Digital Light Processing of Liquid Crystal Elastomers for Self-Sensing Artificial Muscles. Sci. Adv. 2021, 7, 3677-3700.

(28) Ren, L.; Li, B.; He, Y.; Song, Z.; Zhou, X.; Liu, Q.; Ren, L. Programming Shape-Morphing Behavior of Liquid Crystal Elastomers via Parameter-Encoded 4D Printing. ACS Appl. Mater. Interfaces 2020, 12, 15562-15572.

(29) Zhai, F.; Feng, Y.; Li, Z.; Xie, Y.; Ge, J.; Wang, H.; Qiu, W.; Feng, W. 4D-Printed Untethered Self-Propelling Soft Robot with Tactile Perception: Rolling, Racing, and Exploring. Matter 2021, 4, $3313-3326$

(30) Pilz da Cunha, M.; Debije, M. G.; Schenning, A. P. H. J. Bioinspired Light-Driven Soft Robots Based on Liquid Crystal Polymers. Chem. Soc. Rev. 2020, 49, 6568-6578.

(31) Zhang, J.; Guo, Y.; Hu, W.; Sitti, M. Wirelessly Actuated Thermo- and Magneto-Responsive Soft Bimorph Materials with Programmable Shape-Morphing. Adv. Mater. 2021, 33, 2100336. 
(32) Li, D.; Wang, S.; He, J.; Zeng, H.; Yao, K.; Gao, Z.; Wu, M.; Liu, Y.; Wang, L.; Xie, Z.; Yu, X. Bioinspired Ultrathin Piecewise Controllable Soft Robots. Adv. Mater. Technol. 2021, 6, 2001095.

(33) Bengisu, M.; Ferrara, M. Motion in Nature and Biomimetic Approaches. Materials that Move; SpringerBriefs in Applied Sciences and Technology, 2018.

(34) Deshpande, A. D.; Xu, Z.; Weghe, M. J. V.; Brown, B. H.; Ko, J.; Chang, L. Y.; Wilkinson, D. D.; Bidic, S. M.; Matsuoka, Y. Mechanisms of the Anatomically Correct Testbed Hand. IEEE/ASME Trans. Mechatronics 2013, 18, 238-250.

(35) Liu, L.; Geng, B.; Sayed, S. M.; Lin, B.-P.; Keller, P.; Zhang, X.Q.; Sun, Y.; Yang, H. Single-Layer Dual-Phase Nematic Elastomer Films with Bending, Accordion-Folding, Curling and Buckling Motions. Chem. Commun. 2017, 53, 1844-1847.

(36) Yang, R.; Zhao, Y. Non-Uniform Optical Inscription of Actuation Domains in a Liquid Crystal Polymer of Uniaxial Orientation: An Approach to Complex and Programmable Shape Changes. Angew. Chem. 2017, 129, 14390-14394.

(37) Yu, L.; Shahsavan, H.; Rivers, G.; Zhang, C.; Si, P.; Zhao, B. Programmable 3D Shape Changes in Liquid Crystal Polymer Networks of Uniaxial Orientation. Adv. Funct. Mater. 2018, 28, 1802809.

(38) Jiang, Z. C.; Xiao, Y. Y.; Tong, X.; Zhao, Y. Selective Decrosslinking in Liquid Crystal Polymer Actuators for Optical Reconfiguration of Origami and Light-Fueled Locomotion. Angew. Chem. 2019, 131, 5386-5391.

(39) de Haan, L. T.; Gimenez-Pinto, V.; Konya, A.; Nguyen, T.-S.; Verjans, J. M. N.; Sánchez-Somolinos, C.; Selinger, J. V.; Selinger, R. L. B.; Broer, D. J.; Schenning, A. P. H. J. Accordion-like Actuators of Multiple 3D Patterned Liquid Crystal Polymer Films. Adv. Funct. Mater. 2014, 24, 1251-1258.

(40) Ma, J.-N.; Zhang, Y.-L.; Han, D.-D.; Mao, J.-W.; Chen, Z.-D.; Sun, H.-B. Programmable Deformation of Patterned Bimorph Actuator Swarm. Natl. Sci. Rev. 2020, 7, 775-785.

(41) Peng, X.; Kuang, X.; Roach, D. J.; Wang, Y.; Hamel, C. M.; Lu, C.; Qi, H. J. Integrating Digital Light Processing with Direct Ink Writing for Hybrid 3D Printing of Functional Structures and Devices. Addit. Manuf. 2021, 40, 101911.

(42) Chen, Y.; Yang, J.; Zhang, X.; Feng, Y.; Zeng, H.; Wang, L.; Feng, W. Light-Driven Bimorph Soft Actuators: Design, Fabrication, and Properties. Mater. Horiz. 2021, 8, 728-757.

(43) Pilz da Cunha, M.; Foelen, Y.; Engels, T. A. P.; Papamichou, K.; Hagenbeek, M.; Debije, M. G.; Schenning, A. P. H. J. On Untethered, Dual Magneto- and Photoresponsive Liquid Crystal Bilayer Actuators Showing Bending and Rotating Motion. Adv. Opt. Mater. 2019, 7, 1801604.

(44) del Pozo, M.; Liu, L.; Pilz da Cunha, M.; Broer, D. J.; Schenning, A. P. H. J. Direct Ink Writing of a Light-Responsive Underwater Liquid Crystal Actuator with Atypical TemperatureDependent Shape Changes. Adv. Funct. Mater. 2020, 30, 2005560.

(45) Timoshenko, S. Analysis of Bi-Metal Thermostats. J. Opt. Soc. Am. 1925, 11, 233.

(46) Sol, J. A. H. P.; Peeketi, A. R.; Vyas, N.; Schenning, A. P. H. J.; Annabattula, R. K.; Debije, M. G. Butterfly Proboscis-Inspired Tight Rolling Tapered Soft Actuators. Chem. Commun. 2019, 55, 17261729.

(47) Pilz da Cunha, M.; van Thoor, E. A. J.; Debije, M. G.; Broer, D. J.; Schenning, A. P. H. J. Unravelling the Photothermal and Photomechanical Contributions to Actuation of Azobenzene-Doped Liquid Crystal Polymers in Air and Water. J. Mater. Chem. C 2019, 7, 13502-13509.

(48) Sol, J. A. H. P.; Sentjens, H.; Yang, L.; Grossiord, N.; Schenning, A. P. H. J.; Debije, M. G. Anisotropic Iridescence and Polarization Patterns in a Direct Ink Written Chiral Photonic Polymer. Adv. Mater. 2021, 33, 2103309.

(49) Schindelin, J.; Arganda-Carreras, I.; Frise, E.; Kaynig, V.; Longair, M.; Pietzsch, T.; Preibisch, S.; Rueden, C.; Saalfeld, S.; Schmid, B.; Tinevez, J.-Y.; White, D. J.; Hartenstein, V.; Eliceiri, K.;
Tomancak, P.; Cardona, A. Fiji: An Open-Source Platform for Biological-Image Analysis. Nat. Methods 2012, 9, 676-682.

(50) Smith, M. ABAQUS/Standard User's Manual, Version 6.9; Dassault Systèmes Simulia Corp, 2009

(51) Ramgopal, A.; Peeketi, A. R.; Annabattula, R. K. Numerical Analysis and Design of a Light-Driven Liquid Crystal Polymer-Based Motorless Miniature Cart. Soft Matter 2021, 17, 7714-7728.

(52) Mehta, K.; Peeketi, A. R.; Sol, J. A. H. P.; Debije, M. G.; Onck, P. R.; Annabattula, R. K. Modeling of Surface Waves in PhotoResponsive Viscoelastic Liquid Crystal Thin Films under a Moving Light Source. Mech. Mater. 2020, 147, 103388. 